\title{
FROM TLS TO HBIM. HIGH QUALITY SEMANTICALLY-AWARE 3D MODELING OF COMPLEX ARCHITECTURE
}

\author{
R. Quattrini ${ }^{\text {a, * }}$, E. S. Malinverni ${ }^{\text {a }}$, P. Clini ${ }^{\text {a }}$, R. Nespeca ${ }^{\text {a }}$, E. Orlietti ${ }^{\text {a }}$ \\ ${ }^{a}$ DICEA, Dept. of Civil and Building Engineering and Architecture, Polytechnic University of Marche, Ancona, Italy \\ (r.quattrini, e.s.malinverni, p.clini, r.nespeca)@univpm.it - erika.orlietti@tiscali.it
}

\author{
COMMISSION V, WG V/4
}

KEY WORDS: semantic modeling, 3D accuracy, ontologies, historical architecture, reality based modeling, open source tools

\begin{abstract}
:
In order to improve the framework for 3D modeling, a great challenge is to obtain the suitability of Building Information Model (BIM) platform for historical architecture. A specific challenge in HBIM is to guarantee appropriateness of geometrical accuracy. The present work demonstrates the feasibility of a whole HBIM approach for complex architectural shapes, starting from TLS point clouds.

A novelty of our method is to work in a 3D environment throughout the process and to develop semantics during the construction phase. This last feature of HBIM was analyzed in the present work verifying the studied ontologies, enabling the data enrichment of the model with non-geometrical information, such as historical notes, decay or deformation evidence, decorative elements etc. The case study is the Church of Santa Maria at Portonovo, an abbey from the Romanesque period. Irregular or complex historical architecture, such as Romanesque, needs the construction of shared libraries starting from the survey of its already existing elements. This is another key aspect in delivering Building Information Modeling standards. In particular, we focus on the quality assessment of the obtained model, using an open-source sw and the point cloud as reference. The proposed work shows how it is possible to develop a high quality 3D model semantic-aware, capable of connecting geometrical-historical survey with descriptive thematic databases. In this way, a centralized HBIM will serve as comprehensive dataset of information about all disciplines, particularly for restoration and conservation. Moreover, the geometric accuracy will ensure also reliable visualization outputs.
\end{abstract}

\section{INTRODUCTION}

Building Information Modeling (BIM) is currently used in the architecture \& civil engineering (ACE) to integrate a threedimensional visual model of construction projects and digital data of various fields with properties into a file or a database with a specific format. These platforms allow project designers, project managers, construction units, owners, and clients to view the design through a three-dimensional visual model and to obtain relevant digital data of the project.

In recent times, the HBIM (Historic Building Information Modeling) gives a very interesting research perspective. The main requirement in using BIM for representation and survey of historical architecture is the quality of the model and its reliability regarding the geometry. A second condition involves the addition of a comprehensive database of historical notes regarding each component about materials and changes during the time. If models will be able to meet these requirements, avoiding hard computing processes, in the next years the HBIM will play a key role in restoration, representation and communication of cultural built heritage.

This kind of models offers a lot of advantages in obtaining directly two-dimensional drawings and in the management of a large amount of data concerning each shape.

A specific challenge in $3 \mathrm{D}$ reality-based models is to develop easy methods to obtain BIM models for cultural heritage, which guarantee appropriateness of geometrical accuracy. The present work demonstrates the feasibility of a whole BIM approach for complex architectural shapes starting from point clouds.
A novelty of our method is to work in a 3D environment along the process and to develop the semantic of the model during the construction phase. This last feature of HBIM was analyzed in the present work verifying the studied ontologies, enabling the data enrichment of the model with non-geometrical information, such as: historical notes, decay or deformation evidence as well as decorative elements etc.

The semantic organization is central in BIM software. Thanks to parametric models and their attributes, it is able to establish the geometric framework in which multiple data are shared. In the near future, the data collection of all significant aspects in a $3 \mathrm{D}$ content will allow the HBIM to become the best way to manage the process from survey to restoration. Another way to facilitate the spread of HBIM would come from developing effective supply chains with commercial and common software.

The case study here presented is the Church of Santa Maria at Portonovo (Ancona, Italy), an abbey from the Romanesque period, recently restored (Fig.1). This building presents characteristics, which are remarkable for the period, i.e. the masonry vaults. We decided to focus mainly on these geometric shapes and on the structural module (pillar, column and vault) in developing ontologies. Indeed, we expected the vaults would represent the weakest point in the modeling process. Moreover, the selected structure is able to describe the whole frame of the architecture, if we obtain the appropriate level of detail.

The survey of the church was performed by TLS (Terrestrial Laser Scanning) and the model was built up in Revit software on the point cloud.

\footnotetext{
* Corresponding author. This is useful to know for communication with the appropriate person in cases with more than one author.
} 
The second crucial step was the quality assessment of the $3 \mathrm{D}$ BIM model, through the comparison with point cloud. After the check on the model quality, we conceived and created the theoretical semantic organization. This last step opens further development on a reliable model, that is the semantic implementation with open source software.

Following our work structure, here we explain the overview of the paper: after the state of art, two brief paragraphs follow describing the history and features of the church (3.1) and the survey campaign (3.2). The main paragraph (4) is composed by 3 sub-paragraphs about the modeling phase, accuracy tests and assignment of ontologies and attributes, at the end the conclusion and the future perspective of this work.

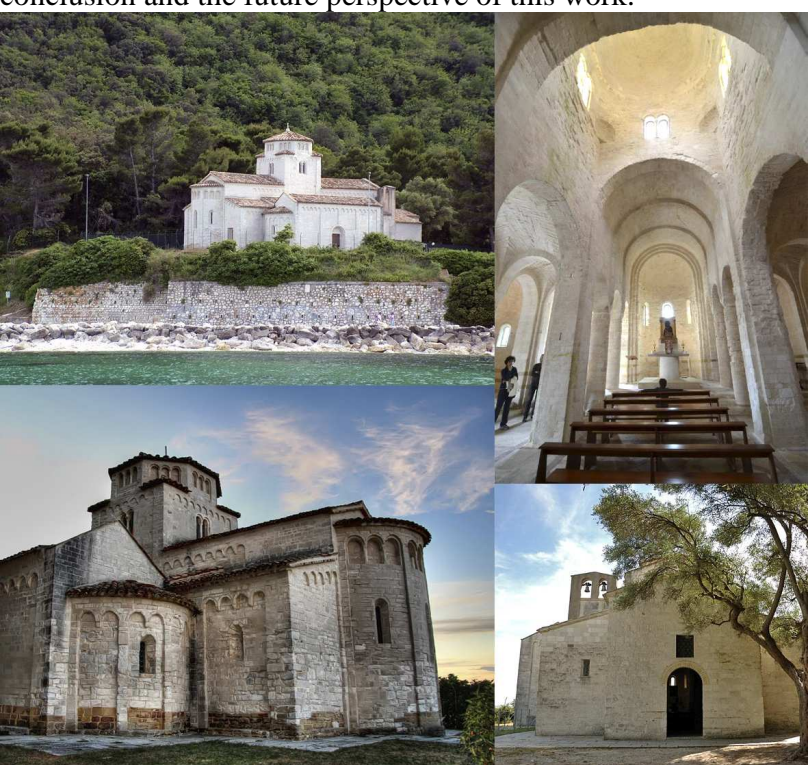

Figure 1. Photos of outdoor and indoor of Church Santa Maria at Portonovo.

\section{STATE OF ART}

In data capturing a robust background in laser scanning acquisition and architectural analysis was developed from some authors in past years (Guidi, 2007). Other works carried out 3-D digital virtual models of ancient heritage monuments from onsite data, developing photogrammetry and especially focusing on data acquisition techniques and color processing methods (Remondino, 2011; Barazzetti, 2010). Some authors obtained a very efficient results integrating various "real-based" modeling methodologies (Fassi, 2011).

In modeling, interesting approaches address to produce a digital document that combines metric and photographic data and historical data in a 3D textured model becoming a theoretical model (Lo Buglio, 2012, Quattrini, 2014) or 3D models that recognise the rules of construction becoming access point to architectural criticism (De Luca et al., 2011; Apollonio, 2013). This last perspective opened the discussion about 3D GIS and its semantics: this is a concept encapsulated in HBIM. Using the BIM one can emphasize the use of a semantic construction of the digital model, not only as a means to modeling a building but as a cognitive system (Apollonio, 2013).

Considering a great challenge to standardize BIM procedures for modeling historic buildings, several works create parametric libraries for historical architecture and perform methods for fast and efficient modeling of building façades (Dore, 2014) or entire buildings (Oreni, 2013). Some studies focus on Level of Detail (LOD), (Fai, 2014), others on automatic extraction of features (Garagnani, 2013). A very interesting development is expected also in considering analogy between treatises and BIM (Apollonio, 2012).

In literature, other works show several steps in 3D HBIM modeling, these workflows (Murphy, 2013; Oreni, 2014) use different software with the necessary format conversion and in the majority we observe a $2 \mathrm{D}$ simplification with slices of point clouds to build up the 3D model.

The BIM approach is very performing for modern buildings, enabling monitoring all phases of life cycle building nowadays. A complete survey (Volk, 2014) on BIM use in new or existing buildings, demonstrates challenging research opportunities arise from process automation and BIM adaption to existing buildings requirements, despite fast developments and spreading standards.

\section{THE ARCHITECTURE AND ITS SURVEY}

\subsection{Brief description of the church}

The Santa Maria at Portonovo church is a very significant heritage from the Romanesque period in the Marche region. The abbey rises up on top of a Conero Mountain cliff, overlooking the sea (Fig.1).

Scholars examined the origins of the Church, finding it difficult to date. More probably, the origins of the building date back to the first half of $11^{\text {th }}$ century, according to a donation to Abbot Paul for the construction of a Benedictine Monastery (document dated 1034). In the next two centuries, the complex was expanded. Perhaps, in 1225 the avant-façade (a sort of a narthex) was built up. In the 1300s, due to a Conero's landslide, the abbey was abandoned. In $16^{\text {th }}$ century, the Turkish invasion destroyed the monastery and the bell tower (Favole, 1993).

Surely, the Church was designed with an overall project, which combined a Greek cross plan with a Latin cross scheme from the Basilica. The Church presents three naves, with seven spans. A rib barrel vault supports the roof of the nave; the crossing vaults cover the lateral naves. Two lateral chapels with tree spans are built up, obtaining the Greek cross scheme. The east end is composed by three circular apses.

Over the crossing of nave and transept, a dome lies on an high drum, with mullioned windows. All the piers are columns, excepting the four pillar (compound rectangular piers) that support the dome. (Piva, 2003).

The outer wall has the typical features of the Romanesque Lombard style with blind arches (niches) along the perimeter.

\subsection{The TLS survey campaign}

The acquisition phase and the point cloud treatment was performed with standard procedures: with laser scanner Leica C10 we arranged 34 scans and 33 scan stations. The survey operations were conducted in Portonovo, over two days (16 hours of work). The weather conditions were cloudy sky and serene at times, which guaranteed a diffused lighting, ideal sky for the taking phase. The photographic campaign was conducted with the integrated camera. To obtain high-quality photographic images and good textures for the model, the b\&w targets were not used as they would have occluded parts of the complex. We 
arranged 6 tilt \& turn target, put on beams; they enabled the link between internal and external scans.

A solid background in all-in-one acquisition with this tool (Clini, 2013) demonstrated advantages in speedy and fast acquisition and low-cost methods of representation. However we designed with attention the survey campaign, considering the requested level of detail and the geometry of the plan, i.e. pillar, span or vault shape and height.

While ensuring the visibility of the whole construction, it was not possible to avoid the shadow cone, due to the presence of objects in the path of the photographic camera. However the decision to set, for each station, a large window of taking has led to a good overlap between scans, covering the holes or the gaps. Having performed terrestrial scans only, the main gap in the point cloud model is in the roofs (Fig. 2).

After acquisition phase, the processing and restitution phase were performed in Cyclone 8.1.3 software. Using the images from internal camera, it is possible to apply colors to single scans (Fig. 3).

The alignment of acquired point clouds was carried out cloud to cloud, by identifying manually control points between scans and with the ICP algorithm. We obtained a 3D model of the whole building composed by $416 \mathrm{mln}$ of points with $0,01 \mathrm{~m}$ RMS of alignment.

After the alignment, we edited the point cloud model during the phases of decimation, cleaning and noise reduction.

Starting from a point cloud model, which included also the RGB value, we tried to carry out the BIM of Santa Maria at Portonovo.

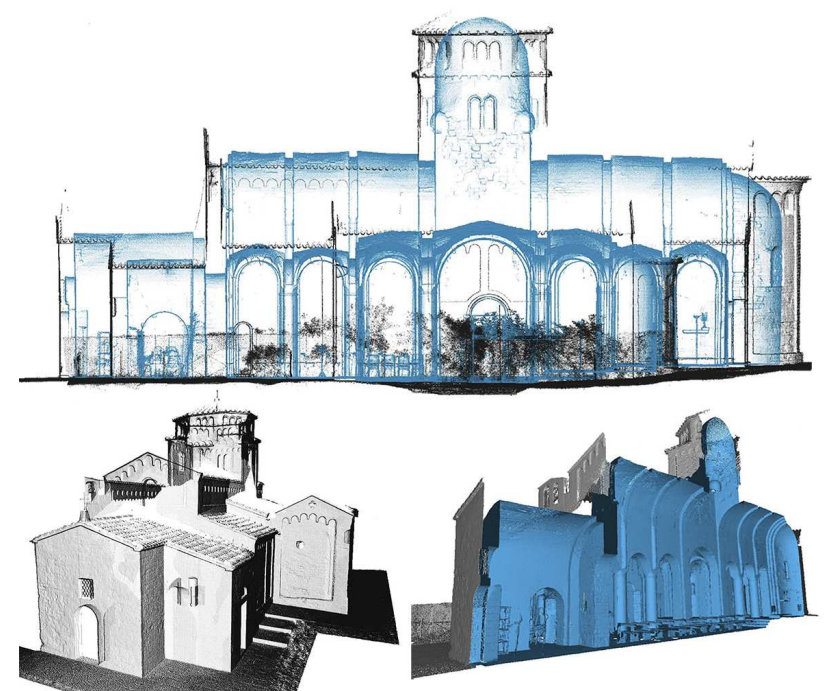

Figure 2. TLS survey of Church Santa Maria at Portonovo.

Aligned Point cloud, exterior (grey) and interior (blue).

\section{HBIM AND QUALITY ASSESSMENT}

In order to improve the framework for 3D modeling, a great challenge is obtain the suitability of Building Information Model (BIM) platform for historical architecture.

Since the architectural heritage has taken advantages from the development of data capturing technologies, an open issue is the integration of BIM systems and data sources for existing buildings, supporting the creation of 3D knowledge and management systems.

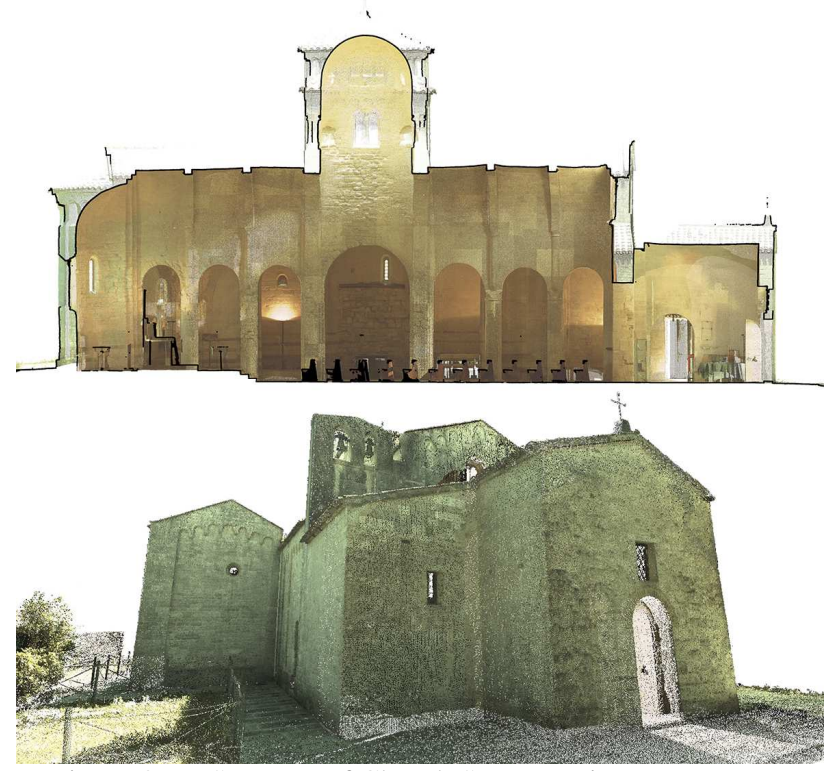

Figure 3. TLS survey of Church Santa Maria at Portonovo. Point cloud mapped with the RGB value of camera acquisition.

\subsection{The modeling phase}

The 3D point cloud, after cleaning and decimation phases, demonstrated himself as a good model for the case study, without artefacts or significant data voids; this database is able to give all information (geometry, material and colour) for the further development of BIM.

A first challenge is to avoid a model simplification too far from the real shape of the objects in BIM platform. Indeed, when components are generated by existing morphologies, complex abstractions have to be introduced. This problem occurs while remodeling elements, both from acquired point clouds by laser scanning equipment and from SFM (Structure From Motion) capturing. Automatic feature extraction in available software is still not effective. In order to verify reliability and usability of methodology for point cloud processing in a BIM environment with high accuracy, we have developed a procedure for the whole architectural complex at Portonovo in Revit 2014.

Since this version, using the $\mathrm{ReCap}^{\mathrm{TM}}$ (Reality Capture) tool, Revit allows a very easy management of the $3 \mathrm{D}$ point cloud data. From Cyclone we obtained a .pts format file, then we exported a .rcs format file, enabling the importation in Revit software.

Our approach performs the model directly on point clouds, minimizing the number of steps, avoiding to lose accuracy, data quality and details. Revit also shows the point cloud in each views (maps, front $\&$ 3D views), due to the encapsulated ReCap tool. In this way we did not need to simplify the building with slices of the point cloud, as well as we did not need a reverse modeling and a polygonalization from the discrete model.

Some objects were made immediately, using the basic commands of the Revit menu. The modeling was performed using parametric elements already in the Revit internal library, some objects were created as families outside, then they were imported into the model. Few libraries are available for free in on-line database. The more complex elements were made in place through B Rep operations. In addition, parametric objects were created specifically for certain items: they will be reused in other similar architecture (Fig. 4). 


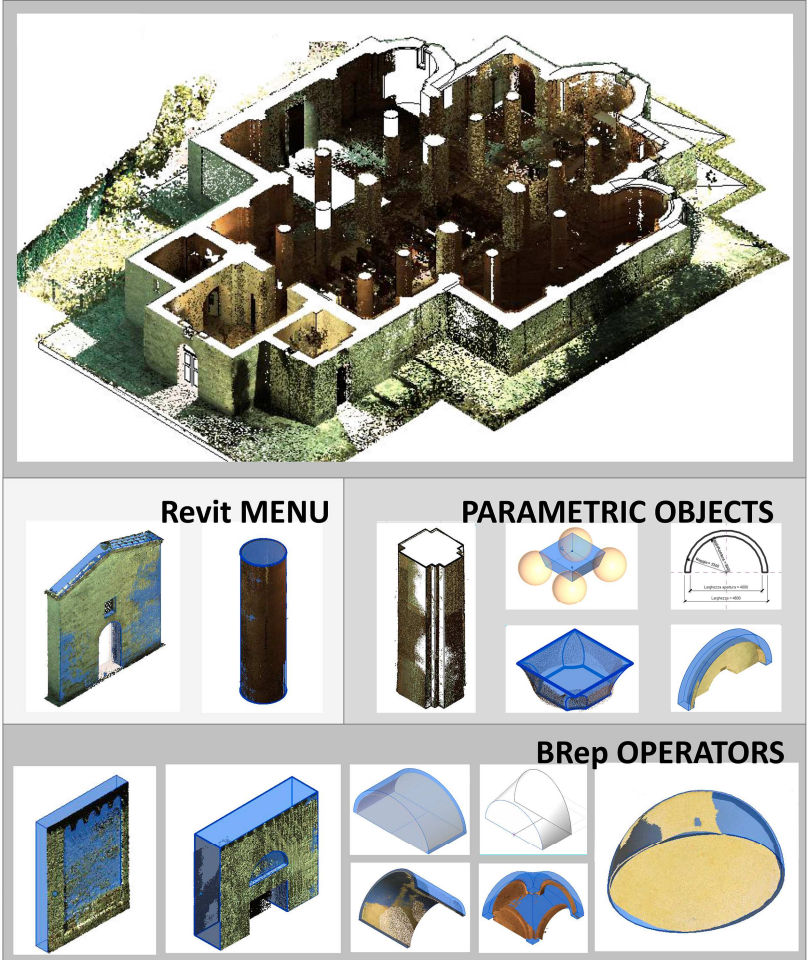

Figure 4. HBIM from point cloud in Revit software. Building methods of architectural shapes

The measures of the contours were extracted from the point cloud by the tool "Measure distance between two references" in different views.

The 3D model was built up in millimeters, according to the coordinate system of the point cloud. A final year student performed the modeling stage, during almost two months.
The walls were created with the tool "Architecture". Along the outer perimeter wall there are several niches (blind arches), typical of Romanesque architecture. The same components were built as local specific. We obtained the niches as empty extrusion.

The modeling of the piers was carried externally by creating families of the "Pillar metric". The piers have been parameterized by the height, the size of the footprint and the number of offsets (with its thickness). This is a very important parametric element for the medieval architecture. Also bases and torus were modeled externally as new families.

The capital was quite simple because it is a block cusion capital. We choose to model it with the "Pillar metric" family. The capital was modeled as a truncated pyramid with a square base. To the latter four balls are subtracted in the corners of the lower base. The profiles were designed according to measures, extracted from the point cloud. Even if the abacus is a rectangular prism, we choose to add parameters in its modeling. This procedure opens a further development: the connection of the proportions between already modeled elements.

The rib vaults (both those in the barrel form and those in cross form) display several problems in the modeling phase; for this reason, we decided to divide vault and rib, like two shapes, then we would have been able to add a link between them, thanks to the Protégé plugin.

The arches and the ribs were modeled by "mass" family, that allowed the change of contour lines. In this way we carried out pointed or segmental or circular arches and vaults. The barrel vaults were obtained by "Special equipment" subtracting each other two full vaults.

A very strong point was to obtain a good geometry that describes the cross vaults: they have a generator non horizontal and they are not regular also in plan (the angles between directrix are not perpendicular).

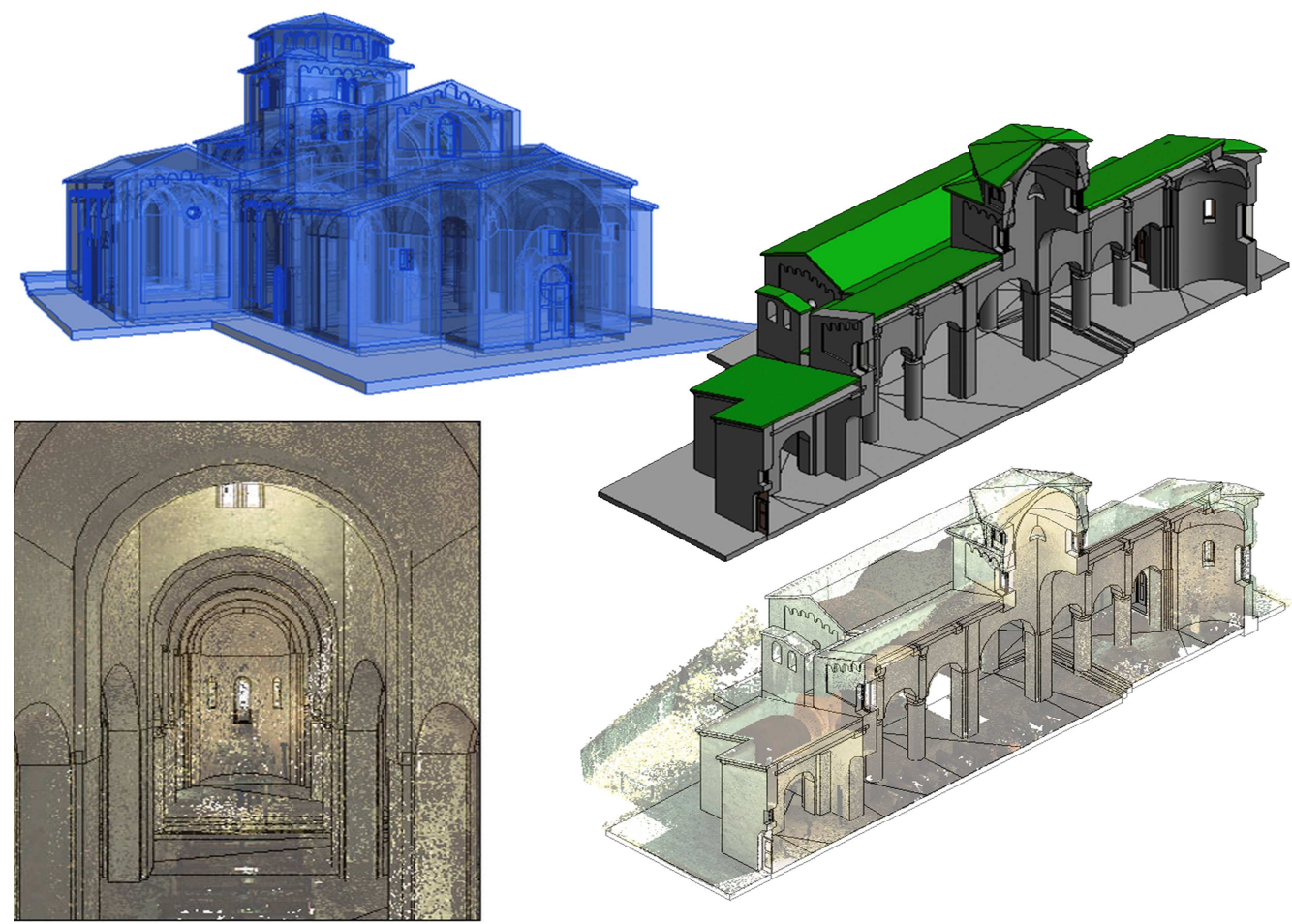

Figure 5. Historical Building Information Model of Santa Maria's Church at Portonovo 
The algorithms that manage intersections in Revit software are not able to perform these irregular shapes. To solve this problem, four full solids and four subtraction solids, as cutting solids, were made, but we observe some artefacts due to errors in Boolean operation. We were not able to add parameter to this kind of vaults, they were tailored to each span. The domes (the principal dome at crossing and the semi-domes over the apses) were modeled like "Special equipment", in composing domes and plans.

From the connection of the several parts, we obtained a BIM model of the church (20 Mb of size) (Fig. 5).

Open points remain in the modeling phase, such as the solid interferences in cross vaults or to complete the parametric management of the order. These issues will be discussed in following works, while the present model is carried out to perform a quality assessment in BIM, regarding a complete building. The main goal of our work was to validate the model, using, as reference database, the point cloud. Only after a positive assessment on the quality of the whole model, we would have proceeded with semantic treatment for the creation of the HBIM.

\subsection{Comparison between point cloud and BIM model}

The qualitative and quantitative assessment of the accuracy for the 3D BIM of Santa Maria at Portonovo was performed with the open source software CloudCompare, using the point clouds as reference. The software is able to compare the point cloud (format file .pts) and the model exported from Revit software (format file .obj).

The whole model was compared and it presented deviations of less than $9 \mathrm{~cm}$ for an amount of $86 \%$, and even reach a level of precision with deviations of less than $3 \mathrm{~cm}$ for an amount of $63 \%$.

These results is appropriate, because also no reference plane (as roofs) or noise elements (as plants) are included in this percentage and average. In order to refine the results, we segmented the point cloud and the model. Another way to improve the comparison is to set a maximum distance for computing.

Then the model was separated, according to its semantic, in several categories (e.g.: columns, pillars, cross vaults, barrel vault, walls, roofs etc.) for punctual or more focused assessment. Columns and vaults are adequately modelled (with average distance of $0.05 \mathrm{~cm}$ and of $0.01 \mathrm{~cm}$ ).

The dome has not a perfect geometric shape, therefore the realized model highlights higher deviations (average distance $6.4 \mathrm{~cm}$ ). This deviation could occur also in CAD modeling, without reverse modeling. The reason of the gap is in deformation of the dome, not represented by an ideal geometry. The analysis here conducted (Fig. 6) is a typical deformation diagram, able to describe damages or carelessness in structural field. The diagram could be attached to the shape as an attribute in BIM and it could become useful for all users of the model.

The greatest differences concern the design of blind arches of the apse due to the lack of curves primitives in B-Rep operation. The numeric results are in the table 7 . The overall average distance is $1.5 \mathrm{~cm}$, in other words we get good quality results for a high percentage.
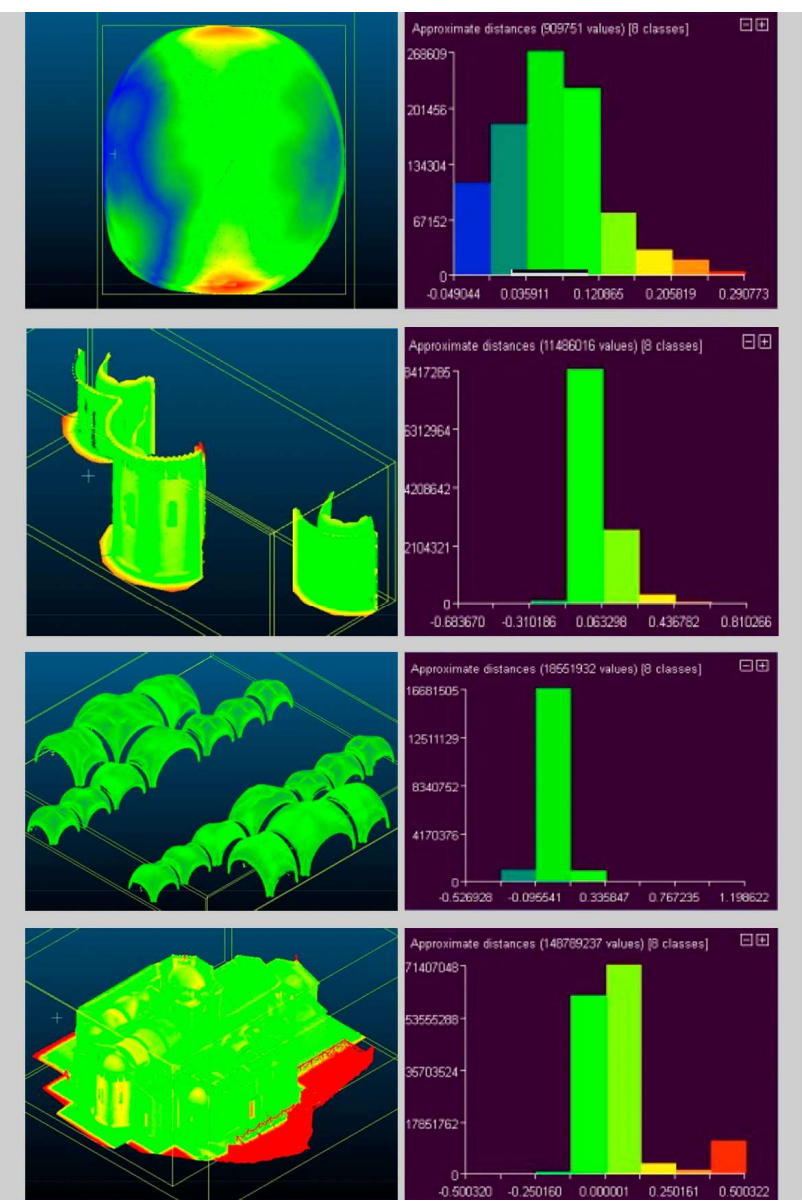

Figure 6. Assessment of 3D BIM accuracy in Cloud Compare software.

The obtained model demonstrated it is possible to build a reality-based 3D model with very good accuracy in BIM environments and without using nurbs operators. This is a crucial step in carrying out standards in order to provide Building Information Modeling new management approaches.

\begin{tabular}{|c|c|c|c|c|c|}
\hline \multirow[b]{2}{*}{ element } & \multirow[b]{2}{*}{$D$ max set } & \multicolumn{2}{|c|}{ histogram } & \multicolumn{2}{|c|}{ Gauss's Curve } \\
\hline & & $\mathbf{D}[\mathrm{cm}]$ & $\%$ & $\begin{array}{c}\mathbf{D}_{\text {media }} \\
{[\mathrm{cm}]}\end{array}$ & $\begin{array}{c}\boldsymbol{\sigma} \\
{[\mathrm{cm}]}\end{array}$ \\
\hline \multirow{2}{*}{$\begin{array}{l}\text { whole } \\
\text { model }\end{array}$} & - & $\mathrm{D}<50$ & 93 & 15,5 & 66,3 \\
\hline & 50 & $\mathrm{D}<12,5$ & 87 & 4,4 & 13,7 \\
\hline dome & - & $-5<D<12$ & 86 & 6,4 & 5,7 \\
\hline $\begin{array}{l}\text { apse - } \\
\text { niches }\end{array}$ & - & $6<\mathrm{D}<25$ & 23 & 3,1 & 9,2 \\
\hline $\begin{array}{l}\text { cross } \\
\text { vaults }\end{array}$ & - & $-9,6<D<12$ & 90 & 0 & 6,7 \\
\hline \multirow{2}{*}{ columns } & - & $-3<\mathrm{D}<6,8$ & 83 & 1,1 & 7 \\
\hline & 6,8 & $\mathrm{D}<3$ & 80 & 0,05 & 3 \\
\hline \multirow{2}{*}{$\begin{array}{l}\text { whole } \\
\text { model }\end{array}$} & \multirow{2}{*}{12} & $\mathrm{D}<9$ & 86 & \multirow{2}{*}{1,5} & \multirow{2}{*}{4,9} \\
\hline & & $D<3$ & 63 & & \\
\hline
\end{tabular}

Table 7. Assessment of 3D BIM accuracy in Cloud Compare software. 


\subsection{Semantic modeling}

In the $3 \mathrm{D}$ model construction, a first semantic partition was made using families and types from Revit: the family refers to models with unique parametric frameworks and can consists in a set of types with different dimension, the single piece are named instances. In the second phase, we studied the relationships among the instances and the types (Fig. 8). The relationships can be horizontal or hierarchical.

The ontology of the church, that is the conceptual system of information related with the geometric model, was carried out and it is a precondition for connection information, such as the construction rules of vaults, the types of ribs, various decorations of capitals, all things that can be the variants. The various data were graphically assigned to each item (Fig. 9). A further development will be the data assignment within Revit through the plug-in Protégé.

Ontologies are increasingly popular among Web developers thanks to the benefits they offer in sharing information. Ontology is intended as a particular conceptual framework or as a specification of a conceptualization (Gruber's definition, 1993).

The most common language in representing ontologies is the OWL. The OWL Web Ontology Language was designed in 2004 for use by applications that needed to process the content of information. OWL facilitates greater machine interpretability of Web content than that supported by XML, RDF, and RDF Schema (RDF-S) by providing additional vocabulary along with a formal semantics (Mc Guinnes, 2004).

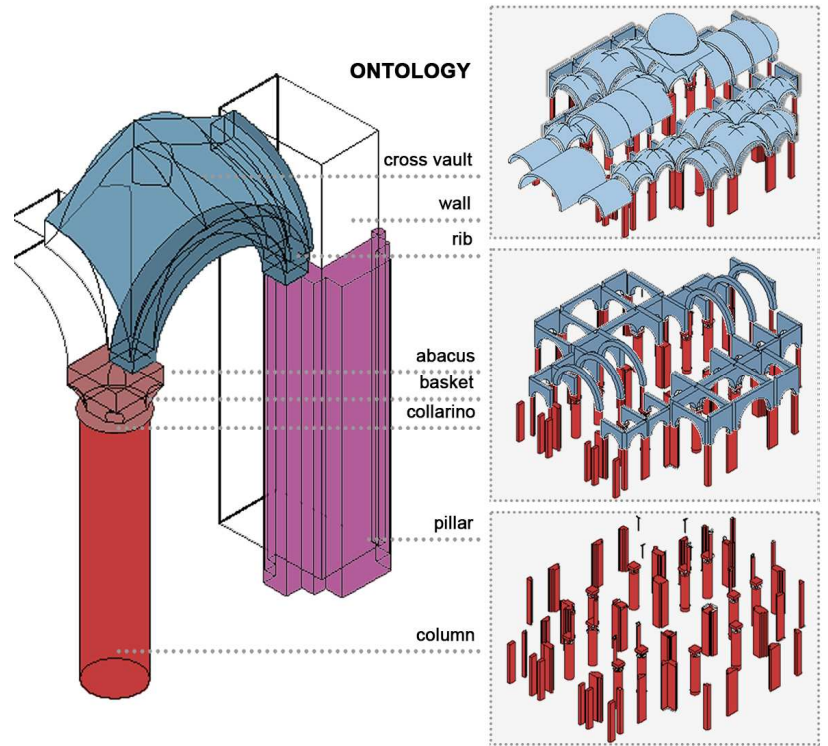

Figure 8. Ontology of whole model and focus on structural module.

OWL Plugins were created in facilitating new practices for building Semantic Web contents, often driven by the needs of and feedback from our users. Among OWL plugins, we choose the open source Protégé plugin. Furthermore, Protégé is flexible open-source platform means that it is easy to integrate customtailored components to build real-world applications (Knublauch, 2004).

It enables aggregation, topological and directional relationships. Aggregation (i.e. part of, belong to, etc.), could be modeled with a hierarchical-based tree representation that permits to describe the composition in a local-to-global way.

Starting from historical notes and several collected analysis (about materials, decorative systems, contact-less or invasive analysis etc.) we arranged a data sheet about each shape.

The operational phases linking parametric object with attributes are now on going.

In addition to in-depth study of the modules of vaults, we focused on attributes and description about the following parts: the avant-façade, the internal arch in a wall of the transept (not visible in external wall), the transept door that linked to the destroyed monastery, the chapel on the right that was a funeral chapel (see the cross on the top of the wall), the external bells substituting the destroyed bell tower.

These are the main elements of modification during the time; their representation in our HBIM could enable a further development of historical analysis and could lead to the qualitative increase in studies about the Church

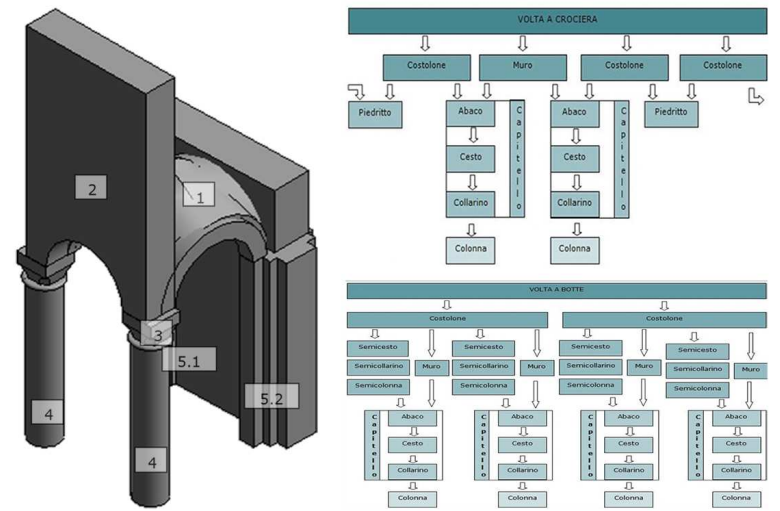

Figure 9. Semantic description of families and types from Revit.

\section{CONCLUSIONS AND FUTURE WORKS}

The work here presented shows that it is possible to develop a high quality 3D model semantic-aware, able to connect geometrical-historical survey with descriptive thematic databases. In this way, a centralized HBIM will serve as comprehensive dataset of information about all disciplines, particularly for restoration and conservation.

BIM's semantic structure enables multiple data enrichment in different levels of category, family, type and instance, out of different motivations. It gave access to various platforms with the goal of long term management of digital cultural heritage.

The main achieved goal is a very reliable quality of the model, combining the efficient representation procedures of Building Information Modeling with high details, starting from complex surveying data. The geometric accuracy obtained will ensure also consistent visualization outputs.

In our opinion, it is imperative to undertake a detailed documentation and representation strategy in BIM environments for cultural heritage. Consequently, it is possible to develop semantics and management procedures in order to determine the correct LoD of the surveying and of the model.

Our work enables a full exploitation of the TLS accuracy, since objects were mapped on to the point cloud in a 3D environment, without slices. 
A specific goal of our approach was to minimize the steps and the format changes along the modeling process, in order to avoid simplification or loss of information. The obtained and validated workflow shows some improvements compared to others in literature (Fig. 10), considering that some procedures involved polygonal model and NURBS operators.

We achieved a good procedure for parametric modelling involving Terrestrial Laser Scanning data, then we verified its suitability and we validated the process thanks to the quality assessment of the model, adopting it in a case of a large monument.

The quality assessment of the BIM model gives very satisfactory results: the whole model presents gaps under $3 \mathrm{~cm}$ in $63 \%$ of points. The outcomes are good also for single elements. The bi-dimensional drawings, automatically extracted from the Revit model, were also evaluated in the case study. They show distances between 2-3 cm from the compared slices, therefore the model is able to represent the building in a 1:100 scale.

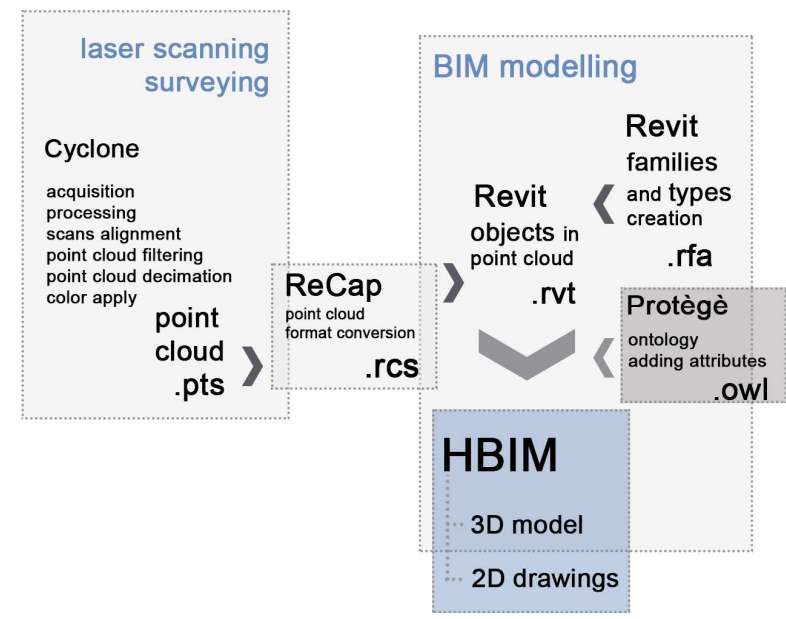

Figure 10. The workflow for HBIM starting from TLS data, minimizing steps and format file

Moreover, another successful aim in our research is to obtain parametric libraries of architectural elements, starting from point clouds or from traditional direct survey.

In HBIM field, several studies faced this issue but a lot of them are referred to classical architecture, particularly they investigated about rules and order in Renaissance age. Irregular or more complex historical architecture, such as Romanesque architecture, needs the construction of shared libraries starting from survey of elements. This is another key aspect in delivering Building Information Modeling standards.

In the construction of parametric libraries of the orders, for example, a further step can involve the study of the proportions between the elements (capital, diameter of column etc.). In several periods of architectural history, the proportions are not fixed or already known, because there are not treatises or theoretical discussions. An interesting point of view in the use of HBIM may occur from collecting parametric libraries of orders and comparing them. That could allow new studies in architectural proportions.
Regarding the description of the elements and its hierarchical organization, we conceived a complete ontology for the case study and we validated it. The prepared ontologies envisage future advances for the classification of the model and the assignment to the individual elements of the metadata collected. An on going work is the conceiving of a comprehensive standard ontology in Romanesque architecture, to compare with the semantic organization of Santa Maria in Portonovo.

The final HBIM product is the creation of full 3D models including detail behind the surface of the object concerning its methods of construction and material make-up. This set of metadata issues from a robust bibliography or in situ analysis.

BIM model serves as a sustainable dataset comprising comprehensive information, and provides access to life-cycle management and potential simulations of various disciplines. For the future, we propose several kind of research to develop in BIM field:

a) study of digital stereotomy; this is a research issue that involves analysis of existing architecture (Oreni, 2013) and new forms of design (Rippmann, 2012)

b) development of environments for collaborating BIM and AR (Augmented Reality) applications; nowadays it is only performed in a very simple architectural building (Heidari, 2014; Brundu, 2014).

Recently, some studies are exploring the real-time communication, the integration of BIM to the site and task conditions, and the interaction of BIM. It is envisaged that AR can fulfil this function effectively through visualizing BIM into the physical context of each construction activity. In the near future, we expect to develop a conceptual framework to investigate how BIM can be extended on site via AR.

In conclusion, a new methodology to build a semantic-aware 3D model of complex architecture is here presented. Starting from point clouds by TLS, we obtained a high quality HBIM, we performed its quality assessment and we developed a procedure for its semantic management. This research promotes the HBIM dissemination. Thanks to exploitation of point cloud, the BIM could become easily an environment that produces full engineering drawings for the conservation of historic structure, including 3D documentation, orthographic projections, sections, details and contracts (energy, cost decay, etc.).

\section{ACKNOWLEDGEMENTS}

The authors would acknowledge the FAI (Italian Ambiental Found) and the Superintendence for Architectural Heritage and Landscape of the Marche Region for allowing the acquisition of the Church of S. Maria at Portonovo. 


\section{REFERENCES}

Apollonio, F. I., Gaiani, M., \& Sun, Z. (2012). BIM-based modeling and data enrichment of classical architectural buildings SCIRES-IT, 2(2), 41-62.

Apollonio, F. I., Baldissini, S., Clini, P., Gaiani, M., Palestini, C., \& Trevisan, C., 2013. The Palladiolibrary geo-models: an open 3D archive to manage and visualize informationcommunication resources about Palladio. ISPRS-International Archives of the Photogrammetry, Remote Sensing and Spatial Information Sciences, 1(2), 49-54.

Apollonio, F. I., Gaiani, M., \& Sun, Z., 2013. 3D Modeling and Data Enrichment in Digital Reconstruction of Architectural Heritage. ISPRS Archives, 5, W2, 43-48

Barazzetti, L., Fangi, G., Remondino, F., and Scaioni, M., 2010. Automation in Multi-Image Spherical Photogrammetry for 3D Architectural Reconstructions. Proceedings VAST 2010. 11th International symposium on virtual reality, archaeology and cultural heritage proceedings. Short and Project Papers, Eurographics Association, Paris, France, 75-81.

Brundu F. G., Patti E., Del Giudice M., Osello A., Macii E., Acquaviva A., 2014. DIMCloud: a distributed framework for district energy simulation and management. In IoTaaS 2014, Lecture Notes of the Institute for Computer Sciences, Social Informatics and Telecommunications Engineering, in press

Clini, P., Quattrini, R., Fiori, F., Nespeca, R., 2013. Integrated Technologies for Surveying Artefacts Damaged by Earthquakes. Application of All-In LIDAR Techniques in the City of L'Aquila. ISPRS Annals of Photogrammetry, Remote Sensing and Spatial Information Sciences, 1(1), 79-84.

De Luca, L., Busayarata, C., Stefania, C., Véron, P., Florenzano, M., 2011. A semantic-based platform for the digital analysis of architectural heritage. Computer \& Graphics, 35 (2): 227-241.

Dore, C, Murphy M, 2014. Semi-automatic generation of asbuilt BIM façade geometry from laser and image data, ITcon, Vol. 19, pg. 20-46, http://www.itcon.org/2014/2

Piva, P., 2003. Marche romaniche, Jaca book, 287 pp.

Fai, S., Rafeiro, J., 2014. Establishing an Appropriate Level of Detail (LoD) for a Building Information Model (BIM)-West Block, Parliament Hill, Ottawa, Canada. ISPRS Annals of Photogrammetry, Remote Sensing and Spatial Information Sciences, 1, 123-130.

Fassi, F., Achille, C., Fregonese, L.,2011. Surveying and modeling the main spire of Milan Cathedral using multiple data sources. The Photogrammetric Record, 26: 462-487.

Favole, P., 1993. Italia Romanica. Le Marche, vol 14, Jaca book, 354 pp.

Garagnani, S., Manferdini, A. M., 2013. Parametric accuracy: Building Information Modeling process applied to the cultural heritage preservation. In International Archive of the
Photogrammetry, Remote Sensing and Spatial Information Sciences, XL, 87-92

Guidi, G., Bianchini, C., 2007. TOF laser scanner characterization for low-range applications. In Electronic Imaging 2007 International Society for Optics and Photonics, 649109-649109.

Heidari, M., Allameh, E., de Vries, B., Timmermans, H., Jessurun, J., \& Mozaffar, F., 2014 . Smart-BIM virtual prototype implementation. Automation in Construction, 39, 134-144.

Knublauch, H., Fergerson, R. W., Noy, N. F., Musen, M. A., 2004. The Protégé OWL plugin: An open development environment for semantic web applications. In The Semantic Web-ISWC 2004,. 229-243. Springer Berlin Heidelberg.

Lo Buglio, D., \& De Luca, L., 2012. Representation of architectural artifacts: definition of an approach combining the complexity of the $3 \mathrm{~d}$ digital instance with the intelligibility of the theoretical model. In SCIRES-IT SCIentific RESearch and Information Technology, Vol 2, Issue 2, 63-76

McGuinness, D. L., Van Harmelen, F., 2004. OWL web ontology language overview. W3C recommendation, 10(10).

Murphy, M., McGovern, E., Pavia, S., 2013. Historic Building Information Modeling-Adding intelligence to laser and image based surveys of European classical architecture. ISPRS journal of photogrammetry and remote sensing,76, 89-102.

Oreni, D., Brumana, R., Cuca, B., \& Georgopoulos, A., 2013. HBIM for conservation and management of built heritage: Towards a library of vaults and wooden bean floors. In CIPA 2013XXV International Symposium, ISPRS Annals, Vol. 164, $1-6$

Oreni, D., Brumana, R., Della Torre, S., Banfi, F., Barazzetti, L., \& Previtali, M., 2014. Survey turned into HBIM: the restoration and the work involved concerning the Basilica di Collemaggio after the earthquake (L'Aquila). ISPRS Annals of Photogrammetry, Remote Sensing and Spatial Information Sciences, 1, 267-273.

Rippmann, M., Block, P., 2012. New design and fabrication methods for freeform stone vaults based on ruled surfaces. In Computational Design Modelling, 181-189. Springer Berlin Heidelberg.

Quattrini, R., \& Baleani, E., 2014. Theoretical background and historical analysis for 3D reconstruction model. Villa Thiene at Cicogna. Journal of Cultural Heritage, In Press, Available online 20 February 2014

Remondino, F., 2011. Heritage Recording and 3D Modeling with Photogrammetry and 3D Scanning. Remote Sensing, Vol. 3(6), pp.1104-1138.

Volk, R., Stengel, J., \& Schultmann, F., 2014. Building Information Modeling (BIM) for existing buildings-Literature review and future needs. Automation in Construction, 38, 109127. 